\title{
Multilayered Extended Release Tablet Dosage Form
}

National Cancer Institute

\section{Source}

National Cancer Institute. Multilayered Extended Release Tablet Dosage Form. NCI

Thesaurus. Code C42963.

A tablet composed of active and/or inert ingredient(s) that have been compressed into multiple layers and is designed to release active and/or inert ingredient(s) at a controlled, prolonged rate so as to reduce dosing frequency. 